\title{
Online - education on YouTube before and after COVID 19. An example study on "Fun Science Romania"
}

\author{
Andreea Mihaela STOICA \\ Bucharest University of Economic Studies, Bucharest, Romania \\ e-mail address: andreeastoica314@gmail.com \\ Cristina VEITH \\ Bucharest University of Economic Studies, Bucharest, Romania \\ e-mail address: christineveith@yahoo.de \\ Marian NECULA \\ Bucharest University of Economic Studies, Bucharest, Romania \\ e-mail address: marian.necula00@gmail.com \\ Paul MARINESCU \\ Bucharest University of Economic Studies, Bucharest, Romania \\ e-mail address: paulmarinescul@gmail.com
}

\begin{abstract}
The article aims to analyze how the public interest of an educational franchise has evolved and how it has been influenced by the pandemic. It compares the evolution of the traffic on the franchise's YouTube channel, Profesorii Trasniti (Nutty Scientists), from two periods of time, "pre" and "post" pandemic, March 2020 being the calendar date taken as a benchmark.

The research methodology includes both a secondary analysis (based on articles published in the literature on topics such as: digitization, education in the virtual environment, social media as a tool in the equation) and a statistical measure of the difference between the proportions of the number of comments on published videos on the YouTube channel "Profesorii Trasniti" (Nutty Scientists) of the Fun Science Romania franchise, "pre" and "post" pandemic based on the data provided by the YouTube Analytics platform.

The questions that arise from this study are:

To what extent has the social media engagement of the "post" pandemic audience on the YouTube channel Profesorii Trasniti (Nutty Scientists) of the Fun Science Romania franchise increased in terms of its educational content?

To what extent has the interest in a strong educational content increased on YouTube compared to the one focused more on entertainment in the pandemic context caused by COVID 19?
\end{abstract}

Keywords: social media, management strategy, business digitization, education, COVID-19 pandemic.

\section{Introduction}

The online education has become the only alternative for both young scholars and students. In this context, we analyzed the extent to which students and teachers used differently, before and after the pandemic, the educational materials in the online environment.

For example, teachers were able to use educational platforms to conduct online classes, such as: Zoom, Discord, Teams, cloud platforms for video and audio conferences, discussions and webinars. Google Meet, the platform integrated in the Google's G Suite Tools suite, was a solution agreed by many teachers.

DOI: $10.2478 /$ picbe-2021-0034

(C) 2021 A. M. Stoica, C. Veith, M. Necula, P. Marinescu, published by Sciendo. This work is licensed under the Creative Commons Attribution 4.0 License. 
Social media platforms, such as Facebook and YouTube, which they used for videos with strong educational content already made on these platforms by different content creators, represented alternatives to complete the materials made available to students.

Social media is an important source of information for young people in general (Zimmermann, 2020). In addition, social media is a very popular source for the young generation today, regardless of the new situation created by the current pandemic. Social media has entered the life of each of us in the last ten years, regardless of the generation we belong to. The literature talks about the importance of social media in both personal and professional life (Effing, 2013). Social media is used both for communication, learning, but also collaboration between individuals and / or organizations (Balakrishnan \& Griffiths, 2017).

Many companies use social media to advertise and promote their products as well as to communicate more directly with customers (Li, Larimo, \& Leonidou, 2021). More and more advertising companies include social media among the tools used to promote their customers. The effects of advertising have been analyzed in various specialized studies, noting that advertising is better received on social media and the cost is lower (Voorveld, van Noort, Muntinga, \& Bronner, 2018). Still very difficult to accept, but proven by various studies, is the fact that certain scientific results are promoting and popularizing them through social media (Mueller-Herbst, Xenos, Scheufele, \& Brossard, 2020).

The educational content in social media platforms is incipient in Romania. It is on an upward trend especially on YouTube, a platform especially known for its use from the perspective of self-education.

The concern for the digitization of education is not a new or unknown phenomenon in the world or which would be due exclusively to the pandemic situation. Until this hour, a long series of different studies have been carried out, with different and very controversial results related to the digitalization of education. However, one direction can be considered of major interest, namely the prior training of teachers for the correct and consistent use of digital tools.

Digitization is largely not actually present in education. The tools used are not the revolutionary ones, mainly related to software elements, but hardware tools, which facilitate and support the old teaching practices (Brun, M .; Hinostroza, J. E., 2014).

Lately, the basic training of future teachers requires the mandatory acquisition of skills to use digital technologies in the educational process to provide all children and young people with access to the education system (Bullock, 2013).

An example is given in the Australian literature. The Australian curriculum is now adapted and oriented towards a more differentiated, more collaborative and creative education system taking into account the opportunities offered by technology (Littlejohn, Ch .; Hunter, J., 2017).

Any change as important in a system as education is full of risks. Some of the risks of misuse of technology can be: ridicule, marginalization, workload or even the exploitation of teachers (Adams, 2018).

\section{Literature review}

\section{Digitalization in education, in the context of COVID 19 pandemic}

The development of the ICT industry and the long line of innovations that have emerged in recent times have been adopted by the young generation around the world with astonishing speed and ease. Today's children have the ability to use the tools of modern technology with great ease. 
Using these tools no longer requires them to be able to read. Mobile tools, such as laptops, tablets and smart phones in combination with cloud applications and virtual communication networks, supported by the internet lay the foundations for teaching and learning in the virtual environment (Barak M .; Ziv S., 2013). Some authors believe that the use of these modern technologies has been slowed down, if not blocked by the reluctance of teachers, who consider the Internet and virtual platforms as factors that distract students from communicating with the teacher (Barak, 2013).

For many students, the use of modern technology in the communication of educational material is an element that arouses their interest. They describe digital materials as interesting, fun and motivating them to learn, provided they are presented and explained correctly by teachers during class. Students want to be guided in the use of digital materials so that they can achieve their teaching goal (Demirkan, 2019). Kuboja and Barak emphasize the importance of initial schooling of teachers for the correct use of modern tools (Kuboja, 2019) (Barak, 2013).

As a result of the transition of the teaching activity from the classical to online system, both teachers and students have faced an increased number of issues that had to be solved and subsequently processed. This has led to an exponential increase in workload, and in some cases to an impact on the quality of the learning process. The lesson plan, content, number of topics offered for discussion were changed in a context in which teachers were completely deprived of prior training for online teaching.

The digitization of the educational process can be implemented through decisions of the external environment (governments, laws, regulations) and / or through initiatives of the internal environment, which are often top-down (Zawakcki-Richter, O.; Latchem, C., 2018).

Students noted that online classes were much more demanding, that they were motivated by modern methods to participate more actively in class, but at the same time that they often did not have access to the information they needed and that they were they got bored in class. There is currently a wide range of digital tools to keep an eye on classes. One of them is the PollEverywhere application, which also had good results in the case of language teaching (Ismail, I.; Elihami, E.; Mustakim, M., 2019).

The older the student, the more important it is to be given the opportunity to develop skills in analysis and synthesis of teaching materials, including independently creating original and valuable materials (Balula, A.; Vasconcelos, S.; Moreira, A., 2019). An important issue for most teachers is self-efficacy. This motivational factor actually means how much self-confidence and ability to perform a task are demonstrated by teachers (Lemon, N .; Garvis, S., 2015).

With the onset of the pandemic, a number of companies have conducted a number of studies, including McKinsey, on the forced transition from traditional to online education. The crisis in the educational environment can be compared to a natural crisis. The two phenomena have in common elements of coordination and global cooperation (Pinner, D .; Rogers, M .; Samandari, H., 2020).

In Europe, the digital transformation has been accelerated by both the pandemic and the new conquests of technology, such as artificial intelligence, robotics, cloud computing and blockchain. Based on several studies and analyzes, the European Commission has set a number of priorities including the use of digital technologies in the learning and teaching process, increasing motivation, creating measures to reduce differences in girls' digital skills compared to boys' skills (European Commission, 2018).

In order to implement the established priorities, one must take into account the most correct administrative conditions and solutions, data security systems, plagiarism and fraud 
detection, data storage and research, access to libraries and other e-learning resources, communication and collaboration between universities (Tømte, CE; Fossland, T.; Aamodt, PO; Degn, L., 2019). In order to have achievements for the digitization of the educational system, it is necessary to train teachers and students (Rienties, B., Brouwer, N .; Lygo-Baker, S., 2013).

Unfortunately, in general, the level of knowledge, digital skills and confidence in their use is at a very low level, even among young people (Podorova, A. et. Al., 2019). Even if, in the general context, the level of digital skills is generally low, we must recognize that students in the "millennial" generation have native digital skills (Wankel, 2009). The development of education in an exclusively virtual system has a number of important limitations, mainly due to the lack of regular interaction with the teacher (Rama Devi, V. N. et. Al., 2019).

\section{Methodology}

This research includes a secondary analysis, based on articles published in the literature on topics such as: digitization, education in the virtual environment and social media as a tool in education. The analyzed articles were taken from databases such as: Springer, Academia.edu, BRILL and Wiley Online Library. Other sources of information were the archives of famous conferences, such as "ICBE", "BASIQ" and "ETIMM". Most of the materials found refer to the phenomenon of education in the virtual system and of the educational tools in social media at a global level and not specific to Romania.

The first method used in this research is a descriptive method in the context in which the subject is a topical one and which has not been studied from this perspective in Romania.

Based on the information collected during the secondary research, YouTube was chosen as the social media platform. From the channels with educational content in Romania, the Fun Science Romania franchise was chosen both from the perspective of the position of market leader on its segment, but also of the relevance of the educational content presented by it. On this example we analyzed whether in the context of the current pandemic there is a change in the behavior of the user of this type of educational material.

Thus, the research continued with the establishment of the main variables, namely the comments of the users of educational content of the Fun Science Romania channel. The variables were: comments, number of views, time period (pre and post pandemic). In the third stage, data extraction, selection, organization and evaluation were used. For data extraction we created an automatic procedure for collecting and processing them using the software package R Selenium (Harrison, 2020).

In formulating the statistical hypothesis, we assume, as a limitation of the study, that the number of comments is not influenced by the differences between the publication dates of the videos, e.g. an older clip may have more than one comment, so it is likely that a video clip will receive a comment, given that a significant amount of time has elapsed since the last sample clip was published at the time of data collection (Dușa, 2014).

The statistical hypotheses formulated on the question regarding the impact that the transition to the online environment has on the school activity, captured through the interaction with the web pages from the YouTube channel and measured with the help of the number of comments, are:

H0: The difference between the proportions of the comments addressed to "pre" and "post" pandemic effects per published video clip is 0 .

H1: The difference between the proportions of the comments addressed to "pre" and "post" pandemic effects per published video clip is different from 0 . 
To test the hypothesis we used the methodology proposed by Efron and Tibshirani (Efron \& Tibshirani, 1993) of the chi-squared independence test augmented with the bootstrapping algorithm applied on the contingent variables "name" and "period", using the chisq.test method. "Exposed by the R stats package (R Project Foundation, 2021).

In this analysis, 239 observations were taken into consideration. Qualitative case study methodology enables researchers to conduct an in-depth exploration of intricate phenomena within some specific context. (Rashid, Rashid, Warraich, Sabir, \& Waseem, 2019).

\section{Results and discussions}

Given the context of online learning and compulsory social distancing, we were interested to see if there are changes in the concerns of YouTube content consumers in Romania in niche educational directions. We chose the field of science because, according to the 2019 PISA tests, Romania recorded disastrous results, ranking 50th, below the European average (Schleicher, 2019). Also, the target audience is the one from the gymnasium, grades V-VIII because the evaluated content is addressed directly through the approached material, more precisely the physics textbook from $6^{\text {th }}$ grade and chemistry, $7^{\text {th }}$ grade, the name of the content being "Fun Science - Stiinta Altfel" on the channel of YouTube "Profesorii Trasniti"(Nutty Scientists).

YouTube channel Profesorii Trasniti (Nutty Scientists) represents the YouTube channel of the Fun Science Romania franchise. It was created in 2016 and its mission is to popularize scientific educational content for children. It currently has over 91,900 subscribers and has accumulated over 7 million views.

There are no creators of similar content in this niche of scientific educational content for high school children in Romania. There are educational content creators such as Zaiafet, "Atentie, cad mere-Attention, Apples fall" that touch the adjacent area of science through curiosities but are not dedicated exclusively to this topic, content creators who promote history as "Proful de Istorie-History Teacher" or scientific content creator - Cristian Presura, whose audience consists of adults over 18 years.

Fun Science Romania is a leader in the market of science promotion services among children, being part, since 2005, of the Fun Science-Nutty Scientists franchise network, existing in the world since 1996. Fun Science Romania offers children scientific, fun and interactive experiences in order to bring them closer to science and to present them with an extremely attractive side of science.

The representative way of the franchise to activate is to offer its services among children, this being no longer possible in the pandemic year 2020.

What remains to be done in the existential path of the organization? Well, it has taken refuge, together with the whole world, in the online environment, more precisely on its YouTube channel opened since 2016, its functionality options suffering unprecedented constraints and limitations.

Following a SWOT analysis, conducted in response to threats, the organization's management chose the Maxi Min strategy (strengths versus threats) among the strengths being listed: a strong presence on social media, highly qualified staff and an extreme brand identity well outlined.

At a time when the entire activity has shrunk massively, it was clear that the survival of the organization will come from the ability to continue to be present in the public's attention and how it could capture the public's attention or if not through solutions that address its problems such as "How can we discover physics or chemistry in the living room?". 
In such a difficult period and without a long horizon, solidarity is a word in the company's strategy: solidarity with the society of which it is part, solidarity with its beneficiaries and solidarity with its customers.

At the time of this research, we are still in the midst of a pandemic crisis, but with enough data already accumulated to be able to get an idea of the organization's audience and social media strategy to be followed.

In order to understand the evolution of traffic on the YouTube channel "ProfesoriiTrasniti" (Nutty Scientists) of the Fun Science Romania brand, we must consider the three dimensions suitable for the organization's marketing objectives: awareness, consideration and action, for which we established three performance indicators as follows:

Table 1. Performance indicators

\begin{tabular}{|l|l|}
\hline \multirow{2}{*}{ Dimensions } & \multicolumn{1}{c|}{ Performance indicators } \\
\hline \multirow{4}{*}{ Awarness } & Views \\
\cline { 2 - 2 } & Impressions \\
\cline { 2 - 2 } Consideration & Subscribers \\
\hline \multirow{4}{*}{ Action } & Likes \\
\cline { 2 - 2 } & Watch Time \\
\cline { 2 - 2 } & Average Views duration \\
\cline { 2 - 2 } & Clicks \\
\cline { 2 - 2 } & Shares \\
\cline { 2 - 2 } & Comments \\
\hline
\end{tabular}

Source: Youtube analytics regarding the channel "Profesorii Trasniti".

We were interested in understanding how the audience under observation interacted with the YouTube channel "Profesorii Trasniti", especially to observe how its interest evolved in terms of the show "Stiinta Altfel - PROGRAMA SCOLARA"( Fun Science-the school program), a show with a strong educational content that addresses the high school curriculum, namely physics and chemistry.

In our analysis, we consider the number of comments as relevant indicator, as a strong proof of interaction in social media. Thus, we chose to analyze one of the strongest performance indicators of the interaction on a YouTube channel, more precisely the one given by the number of comments. Comments can only be given by active participants of the platform, who have accounts. In the case of the channel analyzed by us, the participants turned out to be children who use their parents' accounts.

The above data were provided by the YouTube channel Profesorii Trasniti (Nutty Scientists) through the YouTube analytics platform. They can be found in the tables and figures below, which reflect two different periods of time, namely ten months before the crisis and ten months after the onset of the crisis. The data collected from the YouTube channel "Profesorii Trasniti"(Nutty Scientists) refers to the playlist "Emisiunea Stiinta Altfel - PROGRAMA SCOLARA" (youtube.com, 2021). During the analysis, the videos published between October 2019 - March 2020 (until 11.03.2020) were taken into account. They totaled 13 videos. For the 13 videos, a number of 239 observations were extracted, before and after stopping physical activities in the classrooms.

The list of variables considered in the analysis was as follows:

- "url" - the URL of the video clip;

- "name" - the title of the video;

- "date" - the calendar date the video was published; 
- "comment" - the text content of the written interaction with the respective web page;

- "comment date" - the approximate date of publication of the "comment". YouTube encodes the approximate date as a string of text relative to the current calendar date. Thus, the calendar date of the "comment" is related to days, weeks, months, years, being successively transformed, as time passes, to the calendar time unit with the highest value in the listed list, respectively years;

- "views" - the number of views of the video clip;

- "period" - coding for the calendar date of the comment related to the calendar date of the cessation of physical activity in the classrooms and the migration of the didactic activity in the online environment, i.e. March 2020.

In the coding we used as a time threshold 10 calendar months, in other words comments older than or equal to 10 months from the date of this analysis, January 29, 2021. Specifically, we used as the threshold for coding the variable "periods" March 2020, comments prior to March 2020 being classified as "pre" and comments subsequent to March 2020 classified as "post", March 2020 being the month in which the effects of the pandemic settled. Therefore, they were classified as "pre" effects of the SARS-COV2 pandemic, respectively "post" effects of the pandemic.

Statistically summarized data can be found in Table 2 .

Table 2. Statistical data summary

\begin{tabular}{|l|c|c|c|c|c|c|c|}
\hline \multicolumn{1}{|c|}{ Statistics indicator } & url & name & date & comment & Comment date & views & Period \\
\hline Number of observations & 239 & 239 & 239 & 239 & 239 & 239 & 239 \\
\hline $\begin{array}{l}\text { Unique number of } \\
\text { observations }\end{array}$ & 13 & 13 & 13 & 239 & 239 & 13 & 2 \\
\hline Minimum & NA & NA & NA & NA & NA & 4763 & \\
\hline Q1 & NA & NA & NA & NA & NA & 10605 & \\
\hline Median & NA & NA & NA & NA & NA & 13355 & \\
\hline Average & NA & NA & NA & NA & NA & 13436 & \\
\hline Q3 & NA & NA & NA & NA & NA & 15303 & \\
\hline Maximum & NA & NA & NA & NA & NA & 20961 & \\
\hline
\end{tabular}

Source: Authors' own research.

We mention that the observations belonging to those who own the Youtube channel have been removed. Also, obscene language is censored on this channel so that it affects the number of comments.

Table 2 summarized the data collected through the YouTube channel Profesorii Trasniti (Nutty Scientists), using statistical summary through the 5 numbers for the statistical variable "views", the numerical variable.

The variables url, name, comment, period are categorical variables and the table contains summaries, the unique observation number for them, respectively: for the URL we have 13 unique observations given the fact that there are 13 web addresses assigned to each clip. For the Name variable, there are 13 unique observations and represent the titles of the videos that contain the topics discussed by each clip.

For the Comment variable, we have 239 unique observations and represent the text related to the interaction written with the web page of each video clip.

For the variable Period, we have 2 unique observations, respectively the coding "before" and "after" the manifestation of the effects of the Sars Cov 2 pandemic on the cessation of physical activity in the classrooms. 
The variables "Date" and "Comment date" contain a unit number of 13 observations and 239 observations (we also replaced in table NA with 239).

The numerical variance "Views" was summarized by means of minimum, quartile 1 , median, mean, quartile 3 and maximum.

For the minimum, we obtained the value of 4763 views related to the video with the fewest views, to a maximum of 20961 views related to the video with the most views.

The value of Quartile 1 is 10605 views, the value of the median is 13355 views, the value of the average is 13436 views and the value of quartile 3 is 15303 views. We notice that the average has a value close to the median and is an unbiased estimator for the center tendency, so we notice from the data set that there are no outlier values of the number of views (aberrant) that affect the average. in figure 1.

The chronological distribution of the number of views, the variable "views" is represented

Figure 1. Chronological distribution of the number of views, variable "views"

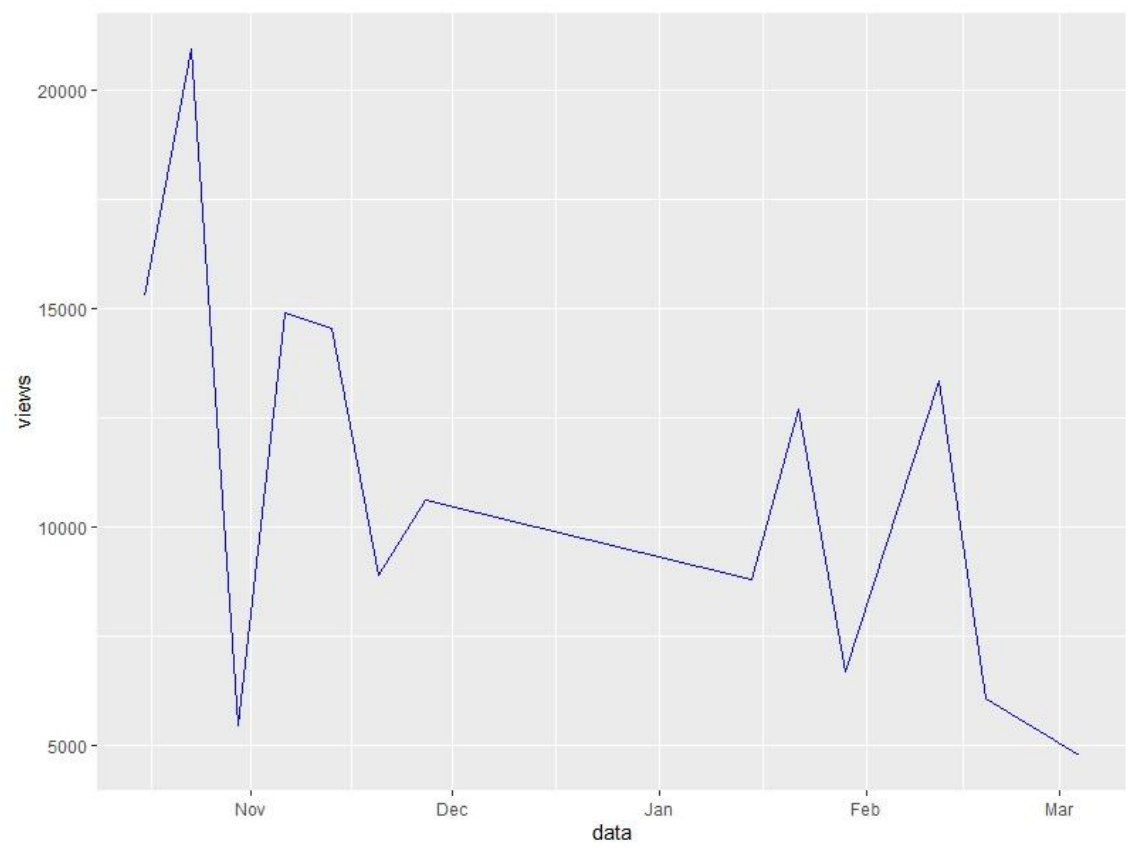

Source: Authors' own research result.

Chronological distribution of the number of views, variable "views", is represented in the figure in which the number of views is reported at the date of publication of the videos.

From figure 1 we notice that the interest assigned to the novelty element of a video measured by the time elapsed from the publication of the clip until now does not usually decrease on a social media channel such as YouTube, where the content must always be fresh and interesting, but on the contrary, we find that the first thematic video uploaded in October 2019 on the channel is also the most viewed at present.

We can thus formulate the hypothesis that the number of views of a video can increase substantially regardless of the time elapsed from the time of publication until now but conditioned by the theme of the video content. In other words, if the topic is current and interesting, the video will continue to attract views regardless of the elapsed time. 
The chronological distribution of the aggregate number of comments per video clip reported on the calendar release date of the video clip is shown in Figure 2.

Figure 2. Number of comments in relation to the publication date of the videoclip

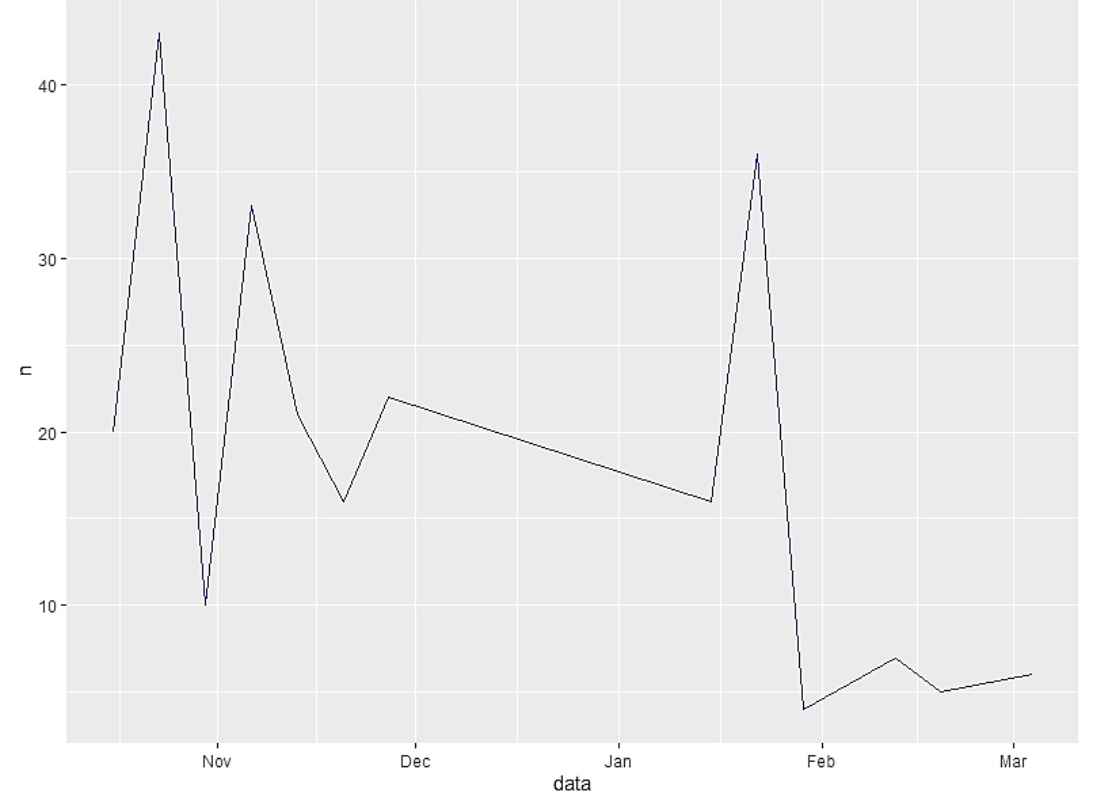

Source: Authors' own research result.

Figure 1. Number of comments reported at the time the videos were released.

Figures 1 and 2 show that a certain part of the videos benefited from a higher number of views compared to the others, respectively, and from a proportionally higher number of interactions through comments, with a decline from mid-January, 2020.

Figure 2 represents Number of comments in relation to the publication date of the video. We notice that the comments of the videos followed the same trend with views, which indicates a strong correlation between views and the number of comments.

Figure 3 shows the aggregate results of the "period" variable used to capture the interaction, through comments, with the web pages of the YouTube channel, before and after the installation of the pandemic effects.

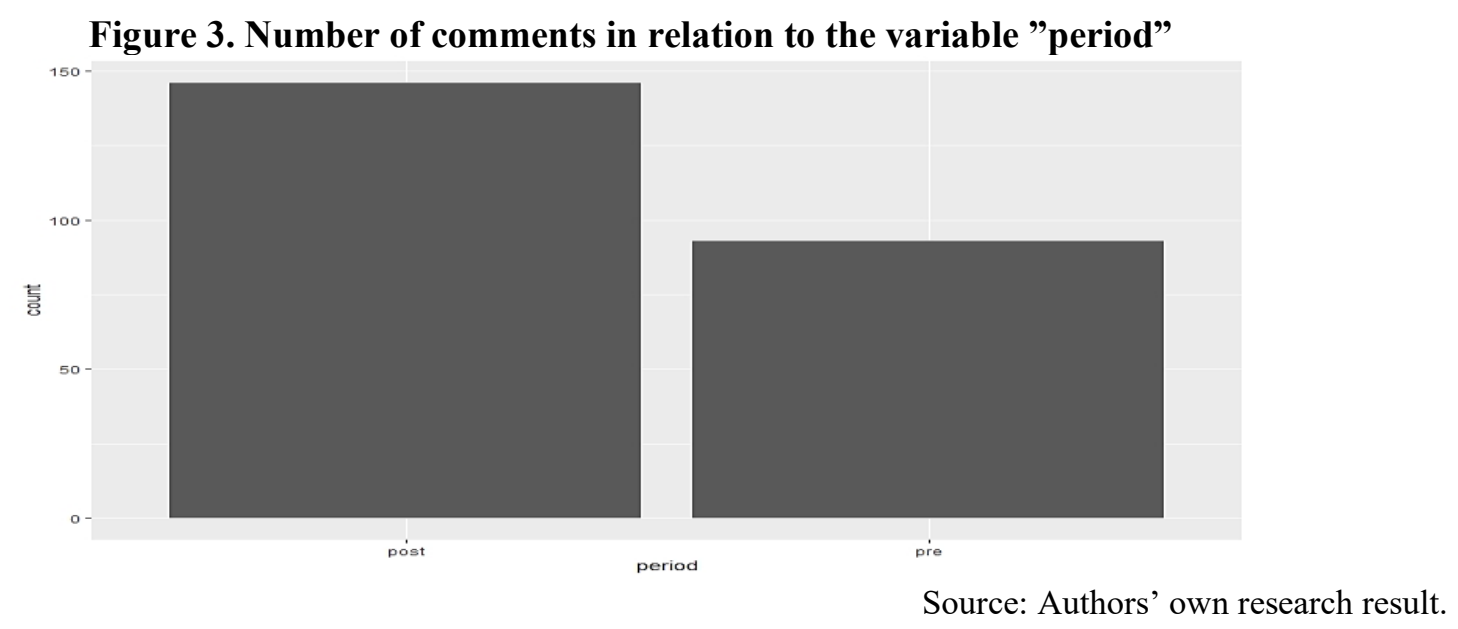


Figure 3 shows the aggregate results of the "period" variable used to capture the interaction, through comments, with the web pages of the YouTube channel, before and after the installation of the pandemic effects. We can see that the number of comments published after March 2020, coded with the value "post" is one third higher than the number of comments published before March 2020, coded with the value "pre".

This results from the statistical research hypothesis that there are differences between the proportion of comments published "post" and the proportion of comments published "pre" March

The results of applying the chi-square test are presented in Table 3, which shows that the data set provides sufficient evidence from a statistical point of view to reject the null hypothesis (H0) and to conclude that there are differences between the proportions of the comments for each video, reported to "pre" and "post" pandemic (H1).

Table 3. Chi-squared test applied to the contingent variables "name" and "period".

Table 3. Chi-squared applied for the variables "name" and "period"

\begin{tabular}{|l|l|}
\hline \multicolumn{2}{|c|}{ Pearson's chi-squared } \\
\hline data & Name Period \\
\hline X-squared & 57.589 \\
\hline df & 12 \\
\hline p-value & $6.187 \mathrm{e}-08$ \\
\hline
\end{tabular}

Source: Authors' own research.

Table 4 shows the observed results versus those expected according to the statistical test, which shows that there are a number of expectations of interactions with the web pages of the Youtube channel after the installation of the effects of the pandemic.

Table 4. Observed versus expected results according to the statistical test before and after COVID-19

\begin{tabular}{|l|l|l|l|l|}
\hline \multirow{2}{*}{ namelperiod } & \multicolumn{2}{c|}{ pre } & \multicolumn{2}{c|}{ expected } \\
\cline { 2 - 5 } & observed & \multicolumn{1}{c|}{ observed } & 26 \\
\hline Chemistry, $7^{\text {th }}$ grade, episode 3 & 7 & 17 & 36 & 20 \\
\hline Chemistry, $7^{\text {th }}$ grade, episode 4 & 8 & 13 & 25 & 9 \\
\hline Chemistry, $7^{\text {th }}$ grade, episode 5 & 14 & 6 & 2 & 9 \\
\hline Chemistry, $7^{\text {th }}$ grade, episode 6 & 11 & 6 & 5 & 2 \\
\hline Chemistry, $7^{\text {th }}$ grade, episode 7 & 2 & 2 & 2 & 4 \\
\hline Chemistry, $7^{\text {th }}$ grade, episode 8 & 4 & 2 & 2 & 12 \\
\hline Physics, $6^{\text {th }}$ grade, episode 2 & 2 & 8 & 18 & 6 \\
\hline Physics, $6^{\text {th }}$ grade, episode 3 & 6 & 4 & 4 & 12 \\
\hline Physics, $6^{\text {th }}$ grade, episode 4 & 8 & 8 & 13 & 13 \\
\hline Physics, $6^{\text {th }}$ grade, episode 5 & 15 & 9 & 7 & 21 \\
\hline Physics, $6^{\text {th }}$ grade, episode 6 & 14 & 14 & 22 & 4 \\
\hline Physics, $6^{\text {th }}$ grade, episode 7 & 0 & 3 & 7 & 3 \\
\hline Physics, 6 ${ }^{\text {th }}$ grade, episode 8 & 2 & 2 & 3 & 2 \\
\hline
\end{tabular}

Source: Authors' own research. 


\section{Conclusion}

The aim of this research was to highlight the growing public interest in educational content on social media platforms such as YouTube.

The results confirm an evolution of the active interest on the YouTube channel Profesorii Trasniti (Nutty Scientists), of the Fun Science Romania franchise, post-pandemic versus prepandemic in terms of the selection of videos studied. Since March 2020, the month in which the whole world took refuge in the house, the interaction in the form of comments on niche videos for the study of physics and chemistry according to the school curriculum has increased considerably.

From the audience's comments, it appears that they were also used as teaching material by teachers in online classes.

Let's remember that "Stiinta Altfel-Programa Scolara" (Fun Science-The school program) appeared on the YouTube channel Profesorii Trasniti (Nutty Scientists) of the Fun Science franchise in 2019, upon the initiative of children subscribed to the channel in response to their problem of lack of understanding of the subject studied in class and lack of access in laboratory experiments. Fun Science Romania came up with an answer to this problem by making this show. The concept of the show is to turn physics and chemistry lessons in the curriculum into fun meetings with nutty professors, full of experiments in accordance with the theory, under the strict supervision of teachers specialized in physics and chemistry. The pandemic and its effects have intensified the need and public interest in this initiative.

According to statista.com, YouTube ranked 2nd in 2020, after Facebook in terms of weekly use of this platform in Romania.

Since its appearance (2005), YouTube has been and remains a platform used for entertainment or educational purposes and after the appearance of the pandemic, the interaction with the activities found on it have intensified. In this context, educational content and beneficiary orientation can mean a strong advantage in any social media strategy, both now and in the near future, for any organization, brand or institution.

We mention as a limitation of the study the inclusion of a single example analyzed from the perspective of one of our initial questions: "To what extent has the interest in a strong educational content increased compared to the one focused more on entertainment, in the pandemic context caused by COVID19?", respectively sample size.

On the other hand, it would be important to continue this study with other examples in which we can test the interaction between the number of views and the "pre" and "post" pandemic period.

We recommend to the Fun Science Romania franchise to continue the series of videos with scientific content in accordance with the school curriculum in order to retain the audience, but also to considerably increase awareness.

It is interesting to research, in the future, how the involvement and development of

educational content published on the YouTube platform during the pandemic will generate customers and profit and also to continue to follow the phenomenon of interest and use of social platforms from educational perspectives.

\section{References}

Adams, P. C. (2018). Geographies of media and communication III: Academic communications and the digital communication environment. (SAGE, Ed.) Progress in Human Geography, 1-10, doi:10.1177/0309132518763849. 
Balakrishnan, J., \& Griffiths, M. D. (2017). Social media addiction: What is the role of content in YouTube? Journal of Behavioral Addictions, 6(3), 364-377, doi:10.1556/2006.6.2017 .058 .

Balula, A.; Vasconcelos, S.; Moreira, A. (2019, November 2). DEVELOPING ACADEMIC SKILLS IN BLENDED ENVIRONMENTS. THE JOURNAL OF TEACHING ENGLISH FOR SPECIFIC AND ACADEMIC PURPOSES, 7(3), 303-309, Retrieved from https://doi.org/10.22190/JTESAP1903303B.

PICBE |

Barak M.; Ziv S. (2013). Wandering: a Web-based platform for the creation of location-based interactive learning objects. Com Educ, 62, 159-170.

Barak, M. (2013, March 22). Closing the Gap Between Attitudes and Perceptions About ICTEnhanced Learning Among Pre-service STEM Teachers. (S. S. Media, Ed.) Journal of Science Education and Technology volume, 23, 1-14, doi:10.1007/s10956-013-9446-8.

Brun, M.; Hinostroza, J. E. (2014, April 12). Learning to become a teacher in the 21st century: ICT integration in Initial Teacher Education in Chile. Educational Technology \& Society, 17(3), 222-238.

Bullock, S. M. (2013). Using digital technologies to support self-directed learning for preservice teacher education. The Curriculum Journal, 103-120.

Demirkan, Ö. (2019, April 18). Pre-service Teachers' Views about Digital Teaching Materials. Educational Policy Analysis and Strategic Research, 14(1), 40-60, doi:10.29329/ epasr.2019.186.3.

Dușa, A. (2014). Elemente de analiză comparativă. București: Tritonic. doi:ISBN 978-606-749004-6.

Effing, R. (2013). SOCIAL MEDIA STRATEGY DESIGN. The 2nd Scientific Conference Information Science In an Age of Change. Enschede, The Netherlands. Retrieved from https://www.researchgate.net/publication/242334919_Social_Media_Strategy_Design.

Efron, B., \& Tibshirani, R. J. (1993). An Introduction to the Bootstrap. (B. Raton, Ed.) Chapter 16.

European Commission. (2018, January 17). Digital Education Action Plan. Brussels: COM.

Harrison, J. J. (2020). RSelenium: R Bindings for 'Selenium WebDriver'. Retrieved January 09, 2021, from https://cran.r-project.org/web/packages/RSelenium/index.html.

Ismail, I.; Elihami, E.; Mustakim, M. (2019, April 30). Students' perceptions of the benefits of mobile polling technology in teaching and learning in college: Implications of student' participation and academic performance, Jurnal Pendidikan Progresif, 9(1), 89-104. doi:10.23960/jpp.v9.i2.201912.

Kuboja, J. M. (2019, May 22). Revamping students' academic performance through the use of information and communication technology in teaching and learning activities: Correlating variables, International Journal of Educational Policy Research and Review, 6(3), 46-53, doi:10.15739/IJEPRR.19.007.

Lemon, N.; Garvis, S. (2015, August 03). Pre-service teacher self-efficacy in digital technology. (Reutledge, Ed.) Teachers and Teaching, 1-22, doi:10.1080/13540602.2015.1058594.

Li, F., Larimo, J., \& Leonidou, L. C. (2021). Social media marketing strategy: definition, conceptualization, taxonomy, validation, and future agenda, Journal of the Academy of Marketing Science, 49, 51-70, doi:https://doi.org/10.1007/s11747-020-00733-3.

Littlejohn, Ch.; Hunter, J. (2017). Messy or not: the role of education institutions in leading successful applications of digital technology in teaching and learning. (AEL, Ed.) Teaching, 38(3), 62-65. 
Mueller-Herbst, J. M., Xenos, M. A., Scheufele, D. A., \& Brossard, D. (2020). Saw It on Facebook: The Role of Social Media in Facilitating Science Issue Awareness. (Sage, Ed.) Social Media + Society, 6(2), doi:10.1177/2056305120930412.

Pinner, D.; Rogers, M.; Samandari, H. (2020). Addressing climate change in a post - pandemic world. McKinsey Quarterly. Retrieved from https://www.mckinsey.com/businessfunctions/sustainability/our-insights/addressing-climate-change-in-a-post-pandemicworld\#.

Podorova, A. et. al. (2019). An important, but neglected aspect of learning assistance in higher education: Exploring the digital learning capacity of academic language and learning practitioners, Journal of University Teaching \& Learning Practice, 16(4), 1-21. Retrieved from https://ro.uow.edu.au/jutlp.

R Project Foundation. (2021). R - stats package. Retrieved January 05, from https://www.rproject.org/.

Rama Devi, V. N. et. al. (2019, May 08). Significance of digital technologies in teaching and learning: a case study on finishing school, griet, Proceedings of International Conference on Digital Pedagogies (ICDP) 2019, 1-10.

Rashid, Y., Rashid, A., Warraich, M. A., Sabir, S. S., \& Waseem, A. (2019). Case Study Method: A Step-by-Step Guide for Business Researchers, International Journal of Qualitative Methods(18), 1-13, doi:10.1177/1609406919862424.

Schleicher, A. (2019). PISA 2018, Insides and Interpretations. OECD.

Tømte, C. E., Fossland, T., Aamodt, P. O., Degn, L. (2019, May 06). Digitalisation in higher education: mapping institutional approaches for teaching and learning. (T. \&. Group, Ed.) Quality in Higher Education, 25:1, 98-114,doi:10.1080/13538322.2019.1603611.

Voorveld, H. A., van Noort, G., Muntinga, D. G., \& Bronner, F. (2018). Engagement with Social Media and Social Media Advertising: The Differentiating Role of Platform Type. (Routledge, Ed.), Journal of Advertising, 47(1), 38-54, doi:10.1080/00913367.2017. 1405754.

Wankel, C. (2009). Management education using social media. Organization Management Journal, 1-12, doi:10.1057/omj.2009.34 · Source: OAI.

youtube.com. (2021, February 02). Profesorii Trăsniți (2021), [Adresa:. Bucharest, Romania. Retrieved from https://www.youtube.com/watch?v=GvZwbXYf00g\&list=PLNMBz7 Gabmug7z0MNRXaKFiz8yp02v8ej.

Zawakcki-Richter, O.; Latchem, C. (2018). Exploring four decades of research in computers and education. Computers \& Education, 136-152.

Zimmermann, D., Noll, C., Gräßer, L., Hugger, K.-U., Braun, L. M., Nowak, T., \& Kaspar, K. (2020). Influencers on YouTube: a quantitative study on young people's use and perception of videos about political and societal topics. Current Psychology. doi:10.1007/s12144-020-01164-7. 